Article

\title{
Characterisation of the First Archaeal Mannonate Dehydratase from Thermoplasma acidophilum and Its Potential Role in the Catabolism of D-Mannose
}

\author{
Dominik Kopp ${ }^{1}$, Robert Willows ${ }^{1,2} \mathbb{D}$ and Anwar Sunna ${ }^{1,2, *(\mathbb{D})}$ \\ 1 Department of Molecular Sciences, Macquarie University, Sydney, New South Wales 2109, Australia; \\ dominik.kopp@hdr.mq.edu.au (D.K.); robert.willows@mq.edu.au (R.W.) \\ 2 Biomolecular Discovery and Design Research Centre, Macquarie University, \\ Sydney, New South Wales 2109, Australia \\ * Correspondence: anwar.sunna@mq.edu.au; Tel.: +61-2-9850-4220
}

Received: 13 February 2019; Accepted: 24 February 2019; Published: 3 March 2019

\begin{abstract}
Mannonate dehydratases catalyse the dehydration reaction from mannonate to 2-keto-3-deoxygluconate as part of the hexuronic acid metabolism in bacteria. Bacterial mannonate dehydratases present in this gene cluster usually belong to the xylose isomerase-like superfamily, which have been the focus of structural, biochemical and physiological studies. Mannonate dehydratases from archaea have not been studied in detail. Here, we identified and characterised the first archaeal mannonate dehydratase (TaManD) from the thermoacidophilic archaeon Thermoplasma acidophilum. The recombinant TaManD enzyme was optimally active at $65^{\circ} \mathrm{C}$ and showed high specificity towards D-mannonate and its lactone, D-mannono-1,4-lactone. The gene encoding for TaManD is located adjacent to a previously studied mannose-specific aldohexose dehydrogenase (AldT) in the genome of T. acidophilum. Using nuclear magnetic resonance (NMR) spectroscopy, we showed that the mannose-specific AldT produces the substrates for TaManD, demonstrating the possibility for an oxidative metabolism of mannose in T. acidophilum. Among previously studied mannonate dehydratases, TaManD showed closest homology to enzymes belonging to the xylose isomerase-like superfamily. Genetic analysis revealed that closely related mannonate dehydratases among archaea are not located in a hexuronate gene cluster like in bacteria, but next to putative aldohexose dehydrogenases, implying a different physiological role of mannonate dehydratases in those archaeal species.
\end{abstract}

Keywords: mannonate dehydratase; mannose metabolism; Thermoplasma acidophilum; mannono-1,4-lactone; 2-keto-3-deoxygluconate; aldohexose dehydrogenase

\section{Introduction}

Mannonate dehydratases (EC 4.2.1.8) catalyse the conversion of mannonate to 2-keto-3-deoxygluconate (KDG) and have been studied as part of the hexuronic acid gene cluster in several organisms, such as Escherichia coli, Bacillus stearothermophilus, Bacillus subtilis and Erwinia chrysanthemi [1-4]. The hexuronate gene cluster encodes enzymes involved in the metabolism of glucuronate and galacturonate [5]. Glucuronate is a common sugar acid present in glucuronoxylan, a constituent of plant cell walls which can serve as the only carbon source for growth of some bacteria $[3,6,7]$. Glucuronate is also present in the mucus layer of mammals, providing a carbon source for anaerobic gut bacteria, such as E. coli $[8,9]$. As part of the hexuronate metabolism, mannonate dehydratase converts mannonate to KDG (Figure 1A). In E. coli, and some species of Erwinia, KDG is phosphorylated and cleaved into pyruvate and 3-phosphoglycerate, which can be further metabolised in the tricarboxylic acid cycle, or the Entner-Doudoroff pathway $[4,5]$. 
Mannonate dehydratases are represented in different enzyme families, such as the xylose isomerase-like superfamily or the enolase superfamily. Mannonate dehydratases encoded in the bacterial hexuronate gene clusters usually belong to the xylose isomerase-like superfamily. Crystal structures have been solved for xylose isomerase-like mannonate dehydratases from Streptococcus suis, E. coli $\mathrm{K} 12$ and Enterococcus faecalis in native form and in complex with $\mathrm{Mn}^{2+}$ ions $[10,11]$. His311 and Tyr325 in the binding pocket were identified as crucial for the activity of the mannonate dehydratases from Gram-positive bacteria, such as S. suis. However, in Gram-negative bacteria (e.g., E. coli K12), an additional inserted sequence in the binding pocket rendered the dehydratase less active [11]. Members of the enolase superfamily show a conserved structure and reaction mechanism, but differ in their physiological functions. Within their conserved barrel structure, mannonate dehydratases of this family share conserved ligand-binding sites for $\mathrm{Mg}^{2+}$, which are essential for the stabilisation of the enediolate intermediate [12]. Among mannonate dehydratases of the enolase superfamily, some representatives with diverse functions have been found, which are involved in the catabolism of sugar acids other than glucuronate or galacturonate [13]. Several crystal structures have been solved for mannonate dehydratases from the enolase superfamily, including enzymes from Chromohalobacter salexigens and Novosphingobium aromaticivorans [12,14]. However, to the best of our knowledge, no archaeal mannonate dehydratase has been investigated so far.

Here, we used genomic analysis to identify the first functional mannonate dehydratase from the thermoacidophilic archaeon Thermoplasma acidophilum (TaManD). The archaeal mannonate dehydratase was recombinantly-expressed in E. coli, purified and functionally characterised. TaManD showed high amino acid sequence identity to bacterial mannonate dehydratases from the xylose isomerase-like superfamily. In the genome of T. acidophilum, the gene encoding for TaManD is located adjacent to an aldohexose dehydrogenase (AldT), which has been shown previously to catalyse the oxidation of mannose to mannonate with high specificity $[15,16]$. However, the physiological significance of the oxidation and its products were not investigated further. We identified the products of an AldT-mediated oxidation of D-mannose using NMR spectroscopy and confirmed that TaManD is able to convert the products to KDG. This demonstrates that in principle, a mannose metabolism based on AldT and ManD is possible in T. acidophilum (Figure 1B).

A

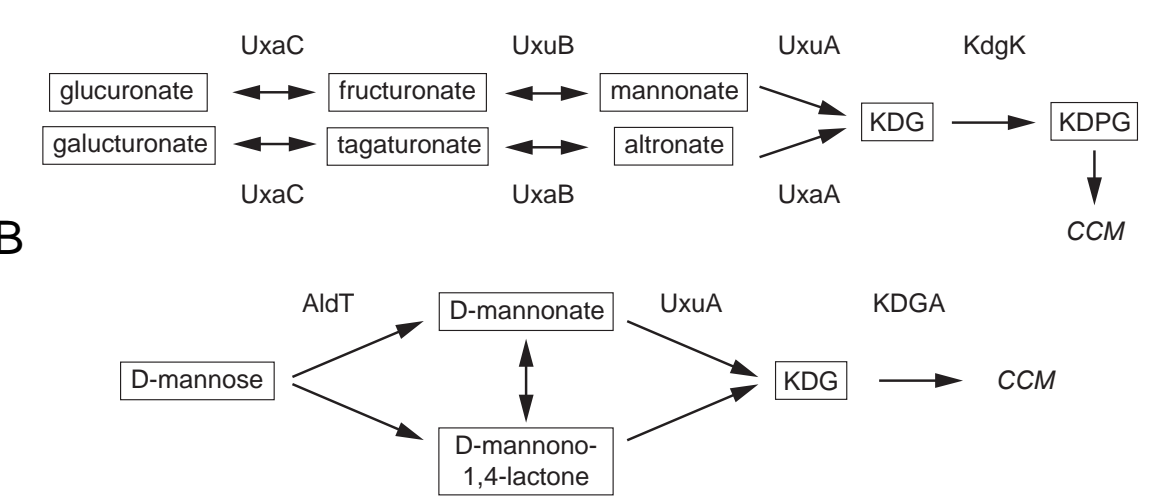

Figure 1. Hexuronate metabolism in E. coli and possible mannose catabolism in T. acidophilum. (A) Role of $u x u A$ mannnonate dehdyratase in dissimilation of hexuronates in E. coli adapted from Peekhaus and Conway [8]. (B) Role of uxuA mannonate dehydratase in a possible mannose metabolism in T. acidophilum. UxaC: hexuronate isomerase, UxuB: mannonate oxidoreductase, UxaB: altronate oxidoreductase, UxuA: mannonate dehydratase, UxaA: altronate dehydratase, KdgK: 2-keto-3-deoxygluconate kinase, KDG: 2-keto-3-deoxygluconate, KDPG: 2-keto-3-deoxy-6-phosphogluconate, AldT: aldose dehydrogenase, KDGA: 2-keto-3-deoxygluconate aldolase, CCM: central carbon metabolism. 


\section{Results and Discussion}

\subsection{Screening for a Functional Mannonate Dehydratase in T. acidophilum}

Based on the previously identified mannose-specific AldT, we searched the genomic neighbourhood of its gene locus (Ta0754) for enzymes which could display activity towards mannonate. In the proximity of Ta0754, several genes are located that encode for hypothetical dehydratases, suggesting their potential to convert mannonate to KDG (Table S1). We identified the protein product of the Ta0753 gene as a functional mannonate dehydratase from T. acidophilum by heterologous expression in E. coli, and compared its properties and genomic context to other previously studied mannonate dehydratases.

Among previously characterised mannonate dehydratases, TaManD shares highest protein sequence identity (31.5\%) with enzymes in the xylose isomerase-like superfamily, such as the mannonate dehydratase from S. suis [10]. Key amino acid residues for substrate binding (His311 and Tyr325) and binding of the cofactor $\mathrm{Mn}^{2+}$ (Asp310, Cys237, His199 and His266) in S. suis are conserved in the amino acid sequence of TaManD. A much higher amino acid sequence identity $(62.9 \%)$ is shared between TaManD and putative mannonate dehydratases from closely related archaeal species, Ferroplasma acidarmanus and Ferroplasma acidiphilum, suggesting an archaeal clade of mannonate dehydratases.

Phylogenetic analysis showed that mannonate dehydratases from T. acidophilum, F. acidarmanus and F. acidiphilum are more closely related to bacterial mannonate dehydratases from the xylose isomerase-like superfamily than to bacterial or archaeal mannonate dehydratases of the enolase superfamily (Figure 2). Mannonate dehydratases of the enolase superfamily have a substantially different structure from those in the xylose isomerase-like superfamily, and therefore, are only distantly related to TaManD. Despite fulfilling a similar function, the dihydroxy-acid dehydratase from $S$. solfataricus, which belongs to the IlvD/EDD superfamily, is rather unrelated to the xylose isomerase-like and enolase superfamilies [17].

For bacterial xylose isomerase-like mannonate dehydratases, a physiological function of the enzyme in the catabolism of hexuronates has been demonstrated $[18,19]$. Although TaManD is annotated as uxuA mannonate dehydratase, which implies a role in the metabolism of hexuronates, it is not present in a classical hexuronate gene cluster known from bacteria such as E. coli, B. subtilis or $B$. stearothermophilus (Figure 3) [2,3]. In contrast, the gene encoding for TaManD is located adjacent to AldT in the genome of T. acidophilum. Similarly, the two closely related putative mannonate dehydratases in F. acidarmanus and F. acidiphilum are also located adjacent to putative aldohexose dehydrogenases. Therefore, a different physiological role can be proposed for these mannonate dehydratases. In the following, we functionally characterise TaManD and show that AldT is able to produce the substrate needed for a subsequent conversion to KDG mediated by TaManD. 


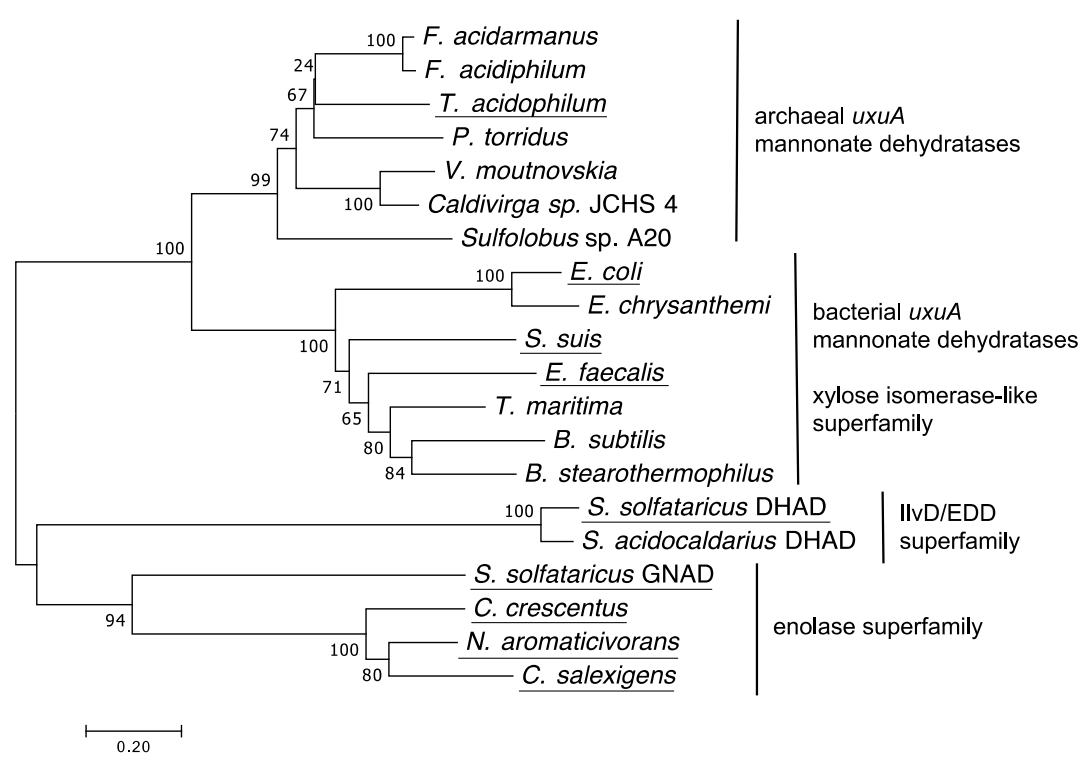

Figure 2. Phylogenetic relationship of different putative and confirmed dehydratases belonging to different enzyme families. Characterised enzymes are underlined. Evolutionary analyses were conducted in MEGA 7. 20 protein sequences were aligned using MUSCLE. The phylogenetic tree was inferred using the neighbour-joining method. The scale bar indicates an evolutionary distance of 0.20 nucleotide per position in the sequence. The number next to the nodes represent bootstrap confidence values estimated from 500 replicates. Protein sequences were retrieved from the Uniprot database and their entry codes are as follows. Ferroplasma acidarmanus: S0AL33, Ferroplasma acidiphilum: A0A1V0N416, Thermoplasma acidophilum: Q9HK52, Picrophilus torridus: Q6L2R9, Vulcanisaeta moutnovskia: F0QYL3, Caldivirga sp. JCHS 4: A0A101XEY7, Sulfolobus sp. A20: A0A1C8ZTN0, Escherichia coli K12: P24215, Erwinia chrysanthemi/Dickeya dadantii: E0SEP1, Streptococcus suis: A0A142UME2, Enterococcus faecalis: Q82ZC9, Thermotoga maritima: Q9WXS4, Bacillus subtilis: O34346, Bacillus stearothermophilus: A0A087LHB3, Sulfolobus solfataricus DHAD: Q97UB2, Sulfolobus acidocaldarius DHAD: Q4J860, Sulfolobus solfataricus GNAD: Q97U27, Caulobacter crescentus/Caulobacter vibroides: Q9AAR4, Novosphingobium aromaticivorans: A4XF23, Chromohalobacter salexigens: Q1QT89.

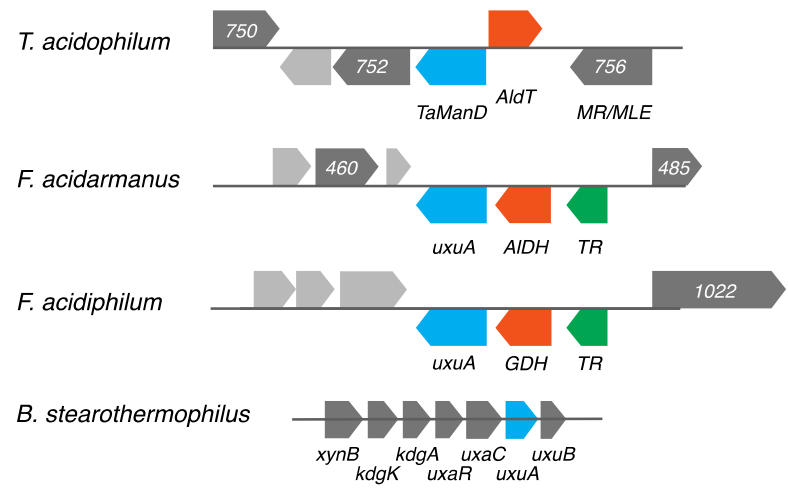

Figure 3. Schematic maps of uxuA mannonate dehydratases and their genomic neighbourhoods in T. acidophilum, F. acidarmanus, F. acidiphilum and B. stearothermophilus. Genes are annotated in the NCBI database as follows: In blue, TaManD/uxuA: T. acidophilum mannonate dehydratase/uxuA D-mannonate dehydratases; in orange, AldT/AlDH/GDH: aldohexose dehydrogenase/aldose dehydrogenase/glucose-1-dehydrogenase; in green, TR: transcriptional regulator; in light grey, annotated as hypothetical protein. Note: 750: FAA hydrolase family protein, 752: L-rhamnonate dehydratase, 756: mandelate racemase/muconate lactonizing enzyme family protein, 460: transposase, 485: acetyl-coenzyme A synthetase, 1022: acetate-CoA ligase, $x y n B: \beta$-xylosidase, $k d g K$ : 2-keto-3-deoxygluconate kinase, $k d g A$ : 2-keto-3-deoxy-6-phosphogluconate aldolase, uxaR: regulatory protein, $u x a C$ : hexuronate isomerase, $u x u B$ : mannonate oxidoreductase. 


\subsection{Substrate Conformation for TaManD Activity}

Before acquiring enzyme kinetics and studying the characteristics of TaManD, we investigated which substrate conformation is encountered by TaManD under physiological conditions. In aqueous solutions, free sugar acids coexist with their lactone in an equilibrium, which is defined by the stability of the lactone, the temperature and the $\mathrm{pH}$ of the solution. Many lactones hydrolyse spontaneously in water, although several lactones, including D-arabinonolactone [20], L-rhamnonolactone [21] and D-xylonolactone [22], have been reported to be hydrolysed by lactonases. Mannonate is able to form a lactone by covalent bond formation between carbon 1 and carbon 5 ( $\delta$-lactone) or carbon 1 and carbon 4 ( $\gamma$-lactone) (Figure 4A). The equilibrium of the two different envelope forms has been studied by NMR spectroscopy and it was found that the $\gamma$-lactone is strongly favoured over the $\delta$-lactone [23]. However, these studies do not describe equilibria between lactone and free acid form in a physiological buffer. In a cellular environment mannonate can either be produced by a mannonate oxidoreductase (UxuB) as part of the catabolism of hexuronic acids or by an aldohexose dehydrogenase, such as AldT, in a hypothetical oxidative mannose catabolism (Figure 1). In order to study the conformation of the substrate for TaManD in a physiological environment, we first acquired decoupled ${ }^{13} \mathrm{C}$ NMR spectra for D-mannono-1,4-lactone in physiological buffer at $\mathrm{pH}$ 7, in its lactone form (incubated with $\mathrm{HCl}$ ) and after hydrolysis to the free sugar acid (incubated with $\mathrm{NaOH}$ ) (Figure 4B). The spectra obtained indicated that the lactone and the free sugar acid can be distinguished by their chemical shifts. In the free sugar acid form, carbon 6 yields a chemical shift at $63.51 \mathrm{ppm}$, whereas in D-mannono-1,4-lactone, carbon 6 displays a chemical shift at 63.02 ppm. D-mannono-1,4-lactone in buffer shows both chemical shifts, indicating that D-mannono-1,4-lactone and D-mannonate are present in an equilibrium at $\mathrm{pH} 7$.

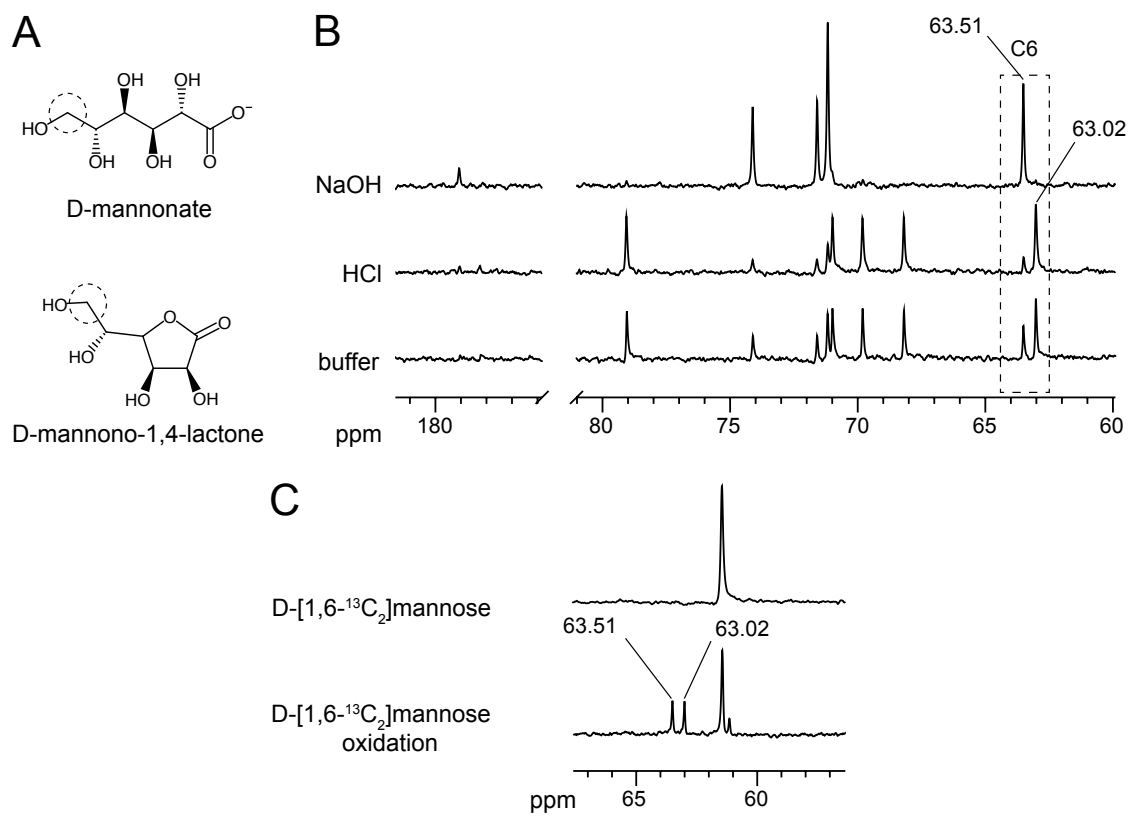

Figure 4. Analysis of D-mannono-1,4-lactone under different conditions and products of AldT-mediated oxidation of isotope labelled D-mannose. (A) Chemical structures of the free sugar acid, D-mannonate, and its lactone, D-mannono-1,4-lactone. Carbon 6, which was used to differentiate the two different substrate forms in NMR spectra, is circled for both structures. (B) Decoupled $1 \mathrm{D}^{13} \mathrm{C}$ NMR spectra of D-mannono-1,4-lactone after incubation in $1 \mathrm{M} \mathrm{NaOH}, 1 \mathrm{M} \mathrm{HCl}$ and in $0.1 \mathrm{M}$ sodium phosphate (NaP) buffer $\mathrm{pH}$ 7. Chemical shift for carbon 6 is shown by a dashed rectangle. Characteristic chemical shifts for the lactone (63.02 ppm) and for the free sugar acid (63.51 ppm) are indicated. (C) Decoupled $1 \mathrm{D}^{13} \mathrm{C}$ NMR spectra before (top) and after (bottom) oxidation of labelled D-mannose with AldT. Chemical shifts of carbon 6 for lactone and free sugar acid are indicated. 
Next, we oxidised isotope-labelled D-[1,6- $\left.{ }^{13} \mathrm{C}_{2}\right]$ mannose using recombinantly-expressed AldT and acquired 1D ${ }^{13} \mathrm{C}$ NMR spectra of the reaction product. The chemical shifts for carbon 6 of mannono-1,4-lactone and D-mannonate were used to analyse the reaction products of the mannose oxidation with AldT, as these were close together but well resolved and will have similar relaxation rates in both forms. The spectrum after partial AldT oxidation of D- $\left[1,6-{ }^{13} C_{2}\right]$ mannose (Figure $4 \mathrm{C}$ ) shows that equal quantities of D-mannono-1,4-lactone and D-mannonate are produced for the subsequent dehydration by TaManD.

\subsection{Expression and Purification of TaManD}

For the further biochemical characterisation, TaManD was expressed together with a tobacco etch virus (TEV) sequence, which allowed the proteolytic cleavage of the His-tag after the first metal affinity purification. In order to study the effect of bivalent metal cofactors on enzyme activity, cleavage of the His-tag from the recombinant enzyme was necessary, since cations $\left(\mathrm{Ni}^{2+}, \mathrm{Mg}^{2+}\right)$ might influence enzyme activity assays of a His-tagged enzyme. After His-tag cleavage, the recombinant enzyme showed a single band on sodium dodecyl sulfate polyacrylamide gel electrophoresis (SDS-PAGE) with an apparent mass of $38 \mathrm{kDa}$ (Figure S1). Peptide mass fingerprinting was performed with liquid chromatography-electrospray ionisation-tandem mass spectrometry (LC ESI MS/MS) and the National Center for Biotechnology Information (NCBI) database searches using the mascot software confirmed the identity of the purified protein as uxuA mannonate dehydratase from T. acidophilum. In addition, the apparent native molecular mass of the protein was estimated from size exclusion chromatography to be $225 \mathrm{kDa}$, indicating a hexameric structure of the protein.

\subsection{Enzyme Characterisation}

Initial tests showed that TaManD lost almost its complete activity after purification, suggesting that essential cofactors for activity were removed during the purification process. Accordingly, the effect of several additives was tested for their influence on the activity of TaManD with D-mannono-1,4-lactone. TaManD showed strongly enhanced activity in the presence of $\beta$-mercaptoethanol and the metal ions $\mathrm{Mn}^{2+}, \mathrm{Ni}^{2+}, \mathrm{Mg}^{2+}, \mathrm{Ca}^{2+}$ and $\mathrm{Co}^{2+}$ (Figure 5). The highest activation $(100 \%)$ was observed in the presence of $\beta$-mercaptoethanol, which was significantly higher than the activating bivalent cation $\mathrm{Ni}^{2+}$ (71.5\% of maximum enzyme activity, p-value: 0.0022$) . \mathrm{Mn}^{2+}, \mathrm{Mg}^{2+}$ and $\mathrm{Co}^{2+}$ also activated TaManD and resulted in 50-60\% increase in maximum activity when compared to the TaManD control (without any additive). No significant difference in activity was observed in the presence of $\mathrm{Fe}^{2+}, \mathrm{Zn}^{2+}, \mathrm{Cu}^{2+}$, EDTA, DTT and glutathione.

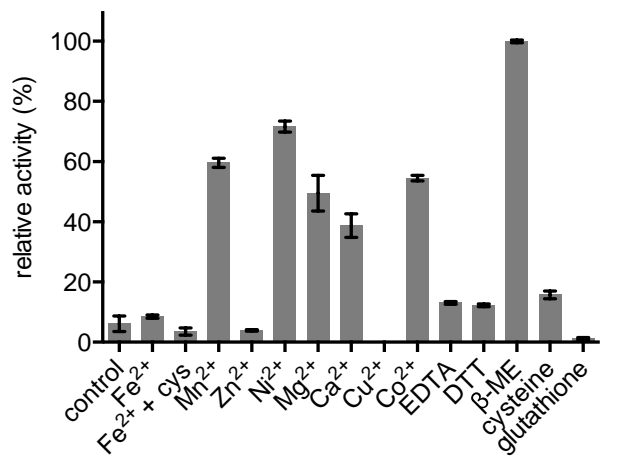

Figure 5. Effect of metal ions, chelating and reducing agents on the activity of TaManD. Purified enzyme $(0.6 \mu \mathrm{g})$ was pre-incubated for $1 \mathrm{~h}$ with $1 \mathrm{mM}$ of each additive in $50 \mathrm{mM}$ HEPES $\mathrm{pH} 7$. Activity was then determined in reactions containing $10 \mathrm{mM}$ D-mannono-1,4-lactone in $50 \mathrm{mM}$ HEPES pH 7 incubated for $1 \mathrm{~h}$ at $55{ }^{\circ} \mathrm{C}$ before analysis with the semicarbazide assay. Activity is expressed in relation to the maximum enzyme activity. $\mathrm{Fe}^{2+}+$ cys: $\mathrm{Fe}^{2+}$ was prepared with $1 \mathrm{mM}$ cysteine. DTT: dithioerythritol, EDTA: ethylendiaminetetraacetate, $\beta$-ME: $\beta$-mercaptoethanol. 
TaManD was activated by similar bivalent ions and reducing factor, as previously studied bacterial mannonate dehydratases from the xylose isomerase-like superfamily. However, none of the bacterial mannonate dehydratases described so far have been shown to have an equally strong activation with both metal ions, $\mathrm{Co}^{2+}$ and $\mathrm{Ni}^{2+}$, as observed with TaManD. Early investigations of mannonate dehydratases focused on E. coli and showed different strengths in activation after incubation with bivalent cations [1,24-26]. In summary, most studies showed that $\beta$-mercaptoethanol, $\mathrm{Fe}^{2+}$ and $\mathrm{Mn}^{2+}$ resulted in highest enzyme activity (90-100\% of maximum enzyme activity). Incubation with other bivalent cations resulted in less activity compared to the enzyme's maximum activity $\left(\mathrm{Co}^{2+}: 27-80 \%\right.$, $\mathrm{Ni}^{2+}: 5-40 \%$ and $\mathrm{Zn}^{2+}: 5-25 \%$, depending on the study). More recently, crystal structures of xylose isomerase-like mannonate dehydratases from S. suis and E. coli have been solved and revealed the presence of primarily $\mathrm{Mn}^{2+}$ and lower amounts of $\mathrm{Mg}^{2+}, \mathrm{Ni}^{2+}$ and $\mathrm{Zn}^{2+}$ in their binding sites [10,11].

T. acidophilum was originally isolated from a hot and acidic environment and accordingly this archaeon displays optimal temperature and $\mathrm{pH}$ for growth at $59{ }^{\circ} \mathrm{C}$ and $\mathrm{pH} 1-2$, respectively [27]. The purified TaManD was active between $35^{\circ} \mathrm{C}$ and $70{ }^{\circ} \mathrm{C}$, with an optimal temperature for activity at $65{ }^{\circ} \mathrm{C}$ (Figure 6A). Thermostability of the enzyme in the absence of substrate was studied at temperatures between $55^{\circ} \mathrm{C}$ and $95^{\circ} \mathrm{C}$ (Figure 6B). The enzyme retains its full activity at $55^{\circ} \mathrm{C}$ for at least an hour, whereas complete inactivation was observed at $75^{\circ} \mathrm{C}, 85^{\circ} \mathrm{C}$ and $95^{\circ} \mathrm{C}$ within $90 \mathrm{~min}$, $60 \mathrm{~min}$ and $15 \mathrm{~min}$, respectively. The difference in the relatively high optimal temperature of the enzyme to the comparably low thermostability indicated that the enzyme is more prone to inactivation in the absence of substrate. Other enzymes obtained from this organism have been shown to display optimal temperatures in the range of $55^{\circ} \mathrm{C}$ to $70^{\circ} \mathrm{C}[15,28-30]$.
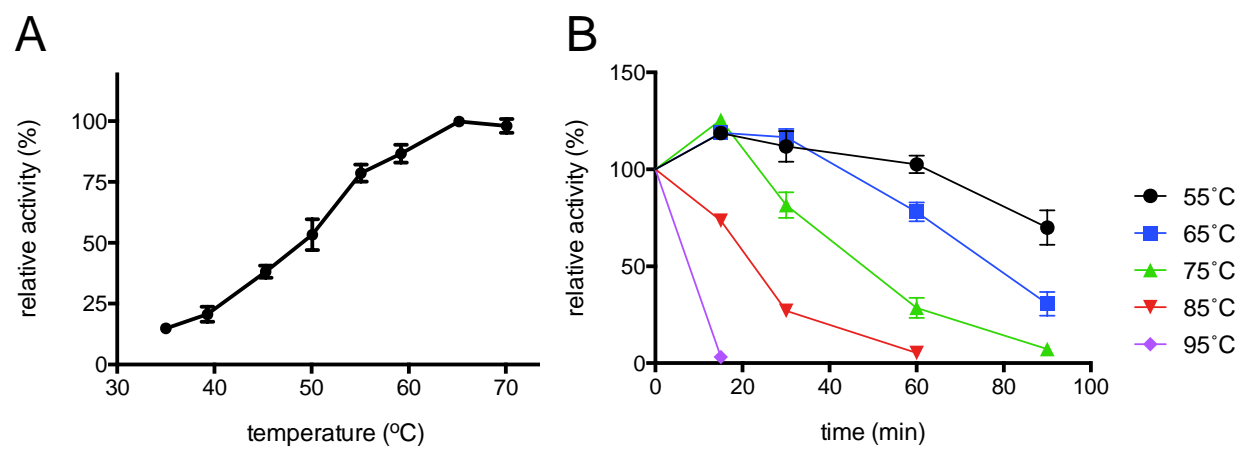

Figure 6. Effect of temperature on TaManD activity. (A) Optimum temperature of TaManD.

(B) Thermostability of purified TaManD enzyme $(1 \mu \mathrm{g})$ incubated over $90 \mathrm{~min}$ at various temperatures.

Following the identification of the crucial metal cofactors required for TaManD activity and determination of its optimal reaction temperature, we acquired enzyme kinetic data for the purified enzyme. Considering the fact that under physiological conditions an equilibrium of both lactone and free sugar acid exists, the kinetic data was acquired in reactions with substrate provided in these two different forms. The substrate was either hydrolysed with $\mathrm{NaOH}$ to obtain free sugar acid, D-mannonate, or the lactone was prepared in buffer, equaling an equilibrium of lactone and free sugar acid. TaManD displayed a higher activity in reactions with D-mannonate compared to reactions with D-mannono-1,4-lactone prepared in buffer at $\mathrm{pH} 7$ (Table 1). The maximal velocity of the reaction, $\mathrm{V}_{\max }$, with D-mannonate as substrate was slightly higher (24-27\%) compared to reactions with the lactone prepared in buffer (p-value: 0.06), whereas no difference in the affinity between the two different forms of the substrate could be observed (Table 1, Figure S2).

The $\mathrm{pH}$ optimum of TaManD was dependent on the form of the substrate. TaManD displayed highest activity between $\mathrm{pH} 5$ and 7 with mannonate, while with D-mannono-1,4-lactone in buffer, the enzyme displayed overall lower activities with an apparent optimum at $\mathrm{pH} 7$ (Figure 7). Unlike previously studied enzymes from T. acidophilum (e.g., AldT), TaManD did not retain maximum activity above $\mathrm{pH} 7$ with both substrates [15]. 
Table 1. TaManD kinetic data with D-mannonate (prepared by hydrolysis with $\mathrm{NaOH}$ ) and with D-mannono-1,4-lactone prepared in buffer ( $\mathrm{pH} 7$ ). Non-linear fitting was performed (Figure S2).

\begin{tabular}{ccccc}
\hline Substrate & $\boldsymbol{K}_{\mathbf{m}}(\mathbf{m M})$ & $\mathbf{V}_{\max }(\mathbf{U} / \mathbf{m g})$ & $\boldsymbol{k}_{\text {cat }}\left(\mathbf{s}^{-\mathbf{1}}\right)$ & $\boldsymbol{k}_{\text {cat }} / \boldsymbol{K}_{\mathbf{m}}\left(\mathbf{m M}^{-\mathbf{1}} \mathbf{s}^{-\mathbf{1}}\right)$ \\
\hline D-mannonate & $5.37 \pm 0.90$ & $2.39 \pm 0.11$ & 1.64 & 0.30 \\
D-mannono-1,4-lactone in buffer & $4.90 \pm 0.53$ & $1.90 \pm 0.06$ & 1.33 & 0.26 \\
\hline
\end{tabular}

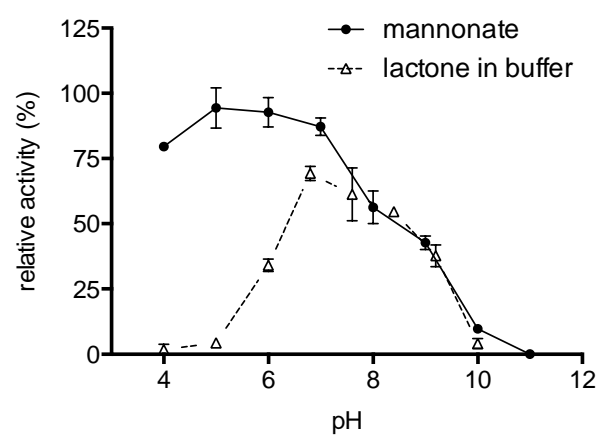

Figure 7. The $\mathrm{pH}$ optima of reactions with D-mannono-1,4-lactone prepared in buffer $\mathrm{pH} 7$ (lactone in buffer) and with D-mannonate (prepared by hydrolysis with $\mathrm{NaOH}$ ). Activity values are expressed as relative activity (\%) normalised to the highest overall activity observed in the assay.

Based on the observations from experiments with different forms of substrate, we assume that D-mannonate is either the only form, or at least more accessible to TaManD than its lactone. At low $\mathrm{pH}$, TaManD shows low activity with D-mannono-1,4-lactone, supposedly because the lactone does not hydrolyse to the free acid. In contrast, if D-mannono-1,4-lactone was hydrolysed to D-mannonate and used as substrate at low $\mathrm{pH}$, high enzyme activity should be observed. Similarly, the difference in $\mathrm{V}_{\max }$ for D-mannonate and D-mannono-1,4-lactone in buffer can be explained by slow hydrolysis of the lactone to the free acid. Reactions with hydrolysed D-mannonate occur faster compared to the lactone in buffer, since more substrate is readily available.

\subsection{Product Identification and Substrate Specificity}

In order to identify the product of the TaManD reaction with mannonate, reactions containing the substrate and $\mathrm{Co}^{2+}$ were analysed at several time points by high-performance liquid chromatography (HPLC) (Figure 8A). Although a complete separation of the product KDG and mannonate could not be achieved on different organic acid columns, an increase of KDG was observed. In order to test for substrate promiscuity, 11 different sugar acids (Figure $8 \mathrm{~B}$ ) were incubated with purified TaManD and tested for the formation of 2-keto-3-deoxy analogues using the semicarbazide assay. D-mannonate and D-mannono-1,4-lactone were the only substrates that showed a positive reaction after incubation for $16 \mathrm{~h}$. This is in contrast to other dehydratases, including members of the enolase superfamily and the IlvD/EDD superfamily, such as the L-fuconate dehydratase from Xanthomonas campestris [31] or the dihydroxy-acid dehydratase from Sulfolobus solfataricus [17,32], which have been shown to be active with a multitude of different sugar acids. 
A

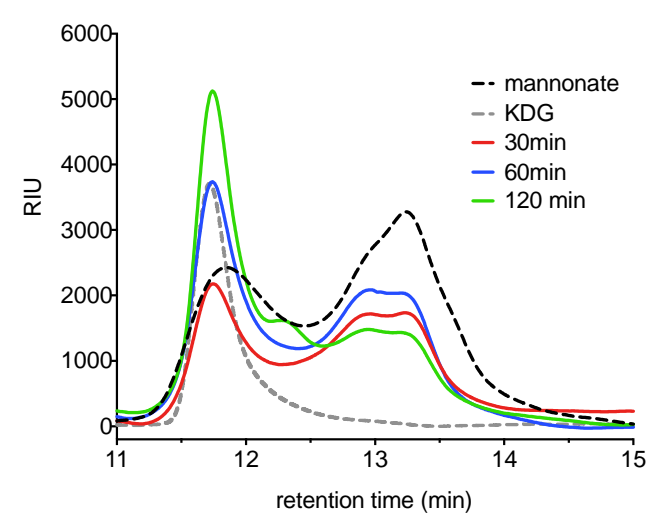

B

\begin{tabular}{ll} 
tested sugar acids & $\begin{array}{l}\text { relative } \\
\text { activity }\end{array}$ \\
\hline D-mannonate & $100 \%$ \\
D-mannono-1,4-lactone & $79 \%$ \\
D-gluconic acid sodium salt & n.d. \\
D-galactono-1,4-lactone & n.d. \\
D-glucuronic acid & n.d. \\
D-galacturonic acid sodium salt & n.d. \\
L-gulonic acid-y-lactone & n.d. \\
D-arabinoic acid sodium salt & n.d. \\
D-fuconic acid lithium salt & n.d. \\
L-fuconic acid sodium salt & n.d. \\
L-rhamnonic acid lithium salt & n.d.
\end{tabular}

Figure 8. Substrate specificity and product analysis of reactions with TaManD. (A) Reactions with TaManD and $10 \mathrm{mM}$ mannonate analysed by HPLC equipped with a refractive index detector. Standards: $10 \mathrm{mM}$ mannonate (dashed black line), $2.5 \mathrm{mM} \mathrm{KDG}$ (dashed grey line). Reactions: stopped after $30 \mathrm{~min}$ (red line), stopped after $60 \mathrm{~min}$ (blue line), stopped after $120 \mathrm{~min}$ (green line). RIU: refractive index units. (B) List of sugar acids that were tested as substrates for TaManD. Activity is expressed relative (\%) to the maximal activity obtained in the assay; n.d.: no signal detected after $16 \mathrm{~h}$ of incubation. Lactones except for D-mannono-1,4-lactone were hydrolysed by incubation in $1 \mathrm{M} \mathrm{NaOH}$ for $1 \mathrm{~h}$ at room temperature and then diluted in 50 mM HEPES pH 7 to obtain free sugar acids. All sugar acids were tested at a concentration of $10 \mathrm{mM}$ in duplicate experiments.

\section{Materials and Methods}

\subsection{Cloning, Expression and Purification of Enzymes}

All plasmids were constructed by amplification of genes from T. acidophilum DSM 1728 genomic DNA (DSMZ, Braunschweig, Germany) using PCR, restriction and ligation into vectors according to standard protocols [33]. Primer pairs and restriction enzymes used for the construction of each expression plasmid are summarised in Table S2. E. coli strain $\alpha$-select (Bioline, Sydney, Australia) was used in all initial cloning procedures. The expression plasmid pProEX HTa-Ta0753 was then used to transform BL21-CodonPlus (DE3)-RIL competent cells (Agilent Technologies, Santa Clara, CA, USA). Plasmid pETDuet-1-AldT was used to transform BL21 (DE3) cells (NEB, Ipswitch, Burlington, MA, USA). BL21-CodonPlus (DE3)-RIL strains containing the respective expression plasmid were grown in $500 \mathrm{~mL}$ Luria-Bertani medium (LB) supplemented with carbenicillin $(100 \mu \mathrm{g} / \mathrm{ml})$ and chloramphenicol $(35 \mu \mathrm{g} / \mathrm{ml})$ at $37^{\circ} \mathrm{C}$ to an $\mathrm{OD}_{600}$ of 0.6 before induction was performed with $0.4 \mathrm{mM}$ isopropyl $\beta$-D-1-thiogalactopyranoside (IPTG) at $20{ }^{\circ} \mathrm{C}$ for $16-18 \mathrm{~h}$. The BL21 (DE3) cells carrying the expression plasmid pETDuet-1-AldT were grown in $500 \mathrm{~mL}$ LB medium containing carbenicillin $(100 \mu \mathrm{g} / \mathrm{ml})$ to an $\mathrm{OD}_{600}$ of 0.5 at $37{ }^{\circ} \mathrm{C}$ before induction was performed with $0.4 \mathrm{mM}$ IPTG at $37^{\circ} \mathrm{C}$ for $4 \mathrm{~h}$. All cultures were harvested by centrifugation at $5000 \times g$ for $20 \mathrm{~min}$, resuspended in $50 \mathrm{mM}$ 4-(2-hydroxyethyl)-1-piperazineethanesulfonic acid (HEPES) pH 7 and lysed by three passages through a French pressure cell. Soluble fractions of the lysates were obtained by centrifugation at $15,000 \times g$ for $20 \mathrm{~min}$. His-tagged enzymes were purified by subjecting the soluble extracts to a $5 \mathrm{~mL}$ nickel-nitrilotriacetic acid (Ni-NTA) affinity column (GE Healthcare) equilibrated with buffer containing $50 \mathrm{mM}$ sodium phosphate (NaP), $300 \mathrm{mM} \mathrm{NaCl}$ and $20 \mathrm{mM}$ imidazole. The proteins were eluted isocratically with a final concentration of $400 \mathrm{mM}$ imidazole. The buffer of the eluates was exchanged to $50 \mathrm{mM}$ HEPES $\mathrm{pH} 7$ by three rounds of centrifugation in Amicon Ultra centrifugal filters (Millipore) with a $30 \mathrm{kDa}$ molecular weight cut-off.

In order to obtain TaManD without a N-terminal His-tag, the enzyme obtained after pProEX HTa-Ta0753 expression and first His-tag purification was incubated with a TEV Protease (Promega, 
Madison, WI, USA). Digestion was performed according to the manufacturer's protocol with addition of $10 \%$ glycerol $\left(\mathrm{v} / \mathrm{v}\right.$, final concentration) and incubation for $1.5 \mathrm{~h}$ at $30^{\circ} \mathrm{C}$ followed by incubation at $4{ }^{\circ} \mathrm{C}$ overnight. Removal of the His-tag and the TEV Protease was achieved by a second Ni-NTA purification using a $1 \mathrm{~mL}$ ZetaSep Ni-NTA affinity column (emp Biotech, Berlin, Germany). The flow-through contained the pure protein and cleavage of the His-tag was verified by SDS-PAGE.

\subsection{Protein Analysis}

Purified proteins were separated by SDS-PAGE using 4-15\% Tris-glycine polyacrylamide gels (Bio-Rad Laboratories, Hercules, USA) and visualised with Coomassie Brilliant Blue. For the identification of TaManD, the single protein band at $38 \mathrm{kDa}$ was excised from the gel and analysed by LC ESI MS/MS at the Australian Proteome Analysis Facility (APAF, Macquarie University), as described elsewhere [34]. Protein identification was performed using the mascot software (2.4.1, Matrixscience, Boston, MA, USA). The native molecular mass of the recombinant protein was determined by size exclusion chromatography on an ÄKTA pure FPLC system using a Superdex Increase 200 10/300 GL column (GE Healthcare) equilibrated with $10 \mathrm{mM} \mathrm{NaP}$ buffer, $140 \mathrm{mM} \mathrm{NaCl}$, $\mathrm{pH}$ 7. A calibration curve was obtained with molecular weight markers thyroglobulin $(669 \mathrm{kDa})$, ferritin $(440 \mathrm{kDa})$, aldolase $(158 \mathrm{kDa})$, conalbumin $(75 \mathrm{kDa})$ and ovalbumin $(43 \mathrm{kDa})$.

\subsection{Nuclear Magentic Resonance (NMR) Analysis}

D-Mannono-1,4-lactone (>95\%) was purchased from TCI Chemicals Co. (Tokyo, Japan). For NMR spectra of the sugar acid in different substrate forms, $1 \mathrm{M}$ D-Mannono-1,4-lactone solutions were prepared in $1 \mathrm{M} \mathrm{NaOH}, 1 \mathrm{M} \mathrm{HCl}$ and in ultrapure water. All solutions were incubated for $1 \mathrm{~h}$ at room temperature, before each solution was diluted to $100 \mathrm{mM}$ using ultrapure water. Then, $300 \mu \mathrm{L}$ of each $100 \mathrm{mM}$ solution (equivalent to $5 \mathrm{mg}$ sugar acid) was freeze-dried and resuspended in $500 \mu \mathrm{L} 0.1 \mathrm{M}$ $\mathrm{NaP}$ buffer, $\mathrm{pH}$ 7. The $\mathrm{pH}$ of all three samples was evaluated prior to NMR analysis. The substrate incubated in $\mathrm{HCl}$ displayed $\mathrm{pH} 6$, while the substrate in water or $\mathrm{NaOH}$ displayed $\mathrm{pH} 7$. After transfer of each sample to $5 \mathrm{~mm}$ NMR tubes, $10 \% \mathrm{D}_{2} \mathrm{O}$ and $40 \mu \mathrm{M}$ 3-(trimethylsilyl)propionic-2,2,3,3-d4 acid (TMSP) chemical shift standard was added. The 1D decoupled ${ }^{13} \mathrm{C}$ NMR spectra of non-isotopically labelled samples were acquired on a $500 \mathrm{MHz}$ Bruker Avance III HD NMR equipped with a BBFO probe at $50{ }^{\circ} \mathrm{C}(323 \mathrm{~K})$, using power-gated proton decoupling with a $90^{\circ}$ pulse with 512 scans and a $3 \mathrm{~s}$ relaxation delay between scans. Oxidation of D-[1,6- $\left.{ }^{13} \mathrm{C}_{2}\right]$ mannose was performed in reactions containing $5 \mathrm{mM}$ of the substrate, $5 \mathrm{mM} \mathrm{NAD}^{+}, 20 \mathrm{mM} \mathrm{NaP}$ buffer at $\mathrm{pH} 7$ and $13.5 \mu \mathrm{g}$ purified AldT. Prior to the addition of purified enzyme and after $30 \mathrm{~min}$ of reaction at $50^{\circ} \mathrm{C}, 1 \mathrm{D}$ power-gated proton decoupled ${ }^{13} \mathrm{C}$ NMR spectra were acquired using a $90^{\circ}$ pulse with 4 scans and a 3 s relaxation delay between scans. Visualisation of all spectra was performed with iNMR 6.0 (http:/ /www.inmr.net). After Fourier transformation and automatic phase correction, an exponential visual weighting factor of 1.5 and a smoothing factor of 10 were applied to all spectra.

\subsection{Enzyme Activity}

D-mannono-1,4-lactone was either used after preparation in $50 \mathrm{mM}$ HEPES at pH 7 (indicated as "lactone in buffer") or after hydrolysis to its free acid form (indicated as "mannonate" or "free sugar acid"). Hydrolysis was performed according to Lamble et al. by preparing $1 \mathrm{M}$ stock solutions of D-mannono-1,4-lactone in $1 \mathrm{M} \mathrm{NaOH}$ and incubation at room temperature for $1 \mathrm{~h}$ before dilutions were prepared in $50 \mathrm{mM}$ HEPES $\mathrm{pH} 7$ [35]. For temperature optimum, $\mathrm{pH}$ optimum and thermostability, activity was quantified using the thiobarbituric acid (TBA) assay, according to a modification by Buchanan et al. [36,37]. Unless stated otherwise, reactions $(60 \mu \mathrm{L})$ contained $0.5-1.5 \mu \mathrm{g}$ pure enzyme, $10 \mathrm{mM}$ mannonate, $50 \mathrm{mM}$ HEPES pH 7 (adjusted at $55^{\circ} \mathrm{C}$ ) and $1 \mathrm{mM} \mathrm{CoSO}_{4}$. Reactions were stopped by incubation on ice or if needed by addition of $6 \mu \mathrm{L} 12.5 \%$ trichloracetic acid (TCA). Next, $50 \mu \mathrm{L}$ of the reaction mixture was oxidised using $125 \mu \mathrm{L}$ of $25 \mathrm{mM}$ periodic acid in $0.25 \mathrm{M} \mathrm{H}_{2} \mathrm{SO}_{4}$ at room temperature for $20 \mathrm{~min}$. The oxidation was stopped by addition of $250 \mu \mathrm{L}$ of $2 \%(\mathrm{w} / \mathrm{v})$ sodium arsenite 
in $0.5 \mathrm{M} \mathrm{HCl}$. Finally, $1 \mathrm{~mL}$ of $0.3 \%$ TBA in water was added to the samples and the reaction mixture was boiled for $10 \mathrm{~min}$. The formation of 2-keto-3-deoxy sugar acid was determined by reading $A_{549 \mathrm{~nm}}$ using 96-well microtiter plates in a Spectrostar Nano plate reader (BMG Labtech, Ortenberg, Germany) and quantified using the molar extinction coefficient of $67.8 \times 10^{3} \mathrm{M}^{-1} \times \mathrm{cm}^{-1}$.

The effect of $\mathrm{pH}$ on enzyme activity was analysed in duplicate reactions with $1 \mu \mathrm{g}$ enzyme and $120 \mathrm{mM}$ universal buffer [38]. Reactions were incubated for $2 \mathrm{~h}$ at $55^{\circ} \mathrm{C}$ before they were analysed with the TBA Assay. In reactions with D-mannono-1,4-lactone in buffer, $\mathrm{pH}$ decreased during the course of the experiment, which was accounted for in the analysis by measurement of the $\mathrm{pH}$ after the reaction. The optimal temperature for enzyme activity was determined in duplicate reactions containing $1 \mu \mathrm{g}$ enzyme. Duplicate reactions were performed for $1 \mathrm{~h}$ at different temperatures before being analysed with the TBA Assay. For thermostability assays, $120 \mathrm{mM}$ universal buffer was used and purified enzyme $(1 \mu \mathrm{g})$ was incubated in duplicates at temperatures between $55^{\circ} \mathrm{C}$ and $95{ }^{\circ} \mathrm{C}$ in the absence of substrate. Samples were removed at different times and the residual activity was measured in reactions with $10 \mathrm{mM}$ mannonate for $45 \mathrm{~min}$ at $55^{\circ} \mathrm{C}$.

The semicarbazide assay was used according to Wichelecki et al. [12] to determine the effect of metal ions, chelators and reducing agents, and the acquisition of Michalis-Menten kinetics $\left(K_{\mathrm{m}}\right.$, $\left.\mathrm{V}_{\max }\right)$. Each reaction $(60 \mu \mathrm{L})$ was incubated with $240 \mu \mathrm{L}$ semicarbazide reagent at room temperature for $1 \mathrm{~h} . A_{250 \mathrm{~nm}}$ was read in a UV transparent microtiter plate (Thermo Scientific, Waltham, MA, USA) using a Spectrostar Nano plate reader. Product formation was quantified using a standard curve of 2-keto-3-deoxygluconate (Sigma-Aldrich, St. Louis, MO, USA) prepared in the same assay buffer. $K_{\mathrm{m}}$, $\mathrm{V}_{\max }$ values were estimated using non-linear fitting in Prism 6 (6.0c, GraphPad software, San Diego, CA, USA). For the effect of metals, chelators and reducing agents, pure enzyme $(0.6 \mu \mathrm{g})$ was incubated with $1 \mathrm{mM}$ of each additive in $50 \mathrm{mM}$ HEPES $\mathrm{pH} 7$ for $1 \mathrm{~h}$ at room temperature. Activity was measured in duplicate reactions containing $10 \mathrm{mM}$ D-mannono-1,4-lactone in $50 \mathrm{mM} \mathrm{HEPES} \mathrm{pH}$ 7, incubated for $1 \mathrm{~h}$ at $55{ }^{\circ} \mathrm{C}$ and then analysed with the semicarbazide assay. Kinetic data for the determination of $K_{\mathrm{m}}$ and $\mathrm{V}_{\max }$ were performed in duplicate reactions $(60 \mu \mathrm{L})$, containing $1 \mu \mathrm{g}$ purified TaManD, $50 \mathrm{mM}$ HEPES pH 7, $1 \mathrm{mM} \mathrm{CoSO}_{4}$ and different substrate concentrations (1-50 mM). Linear increase of reaction product was assured over $1 \mathrm{~h}$ reaction time. Reactions were performed for $45 \mathrm{~min}$ at $55{ }^{\circ} \mathrm{C}$ before product formation was determined using the semicarbazide assay and the KDG standard curve. Substrate specificity was analysed using 11 different sugar acids (Figure $8 \mathrm{~B}$ ). Reactions were performed in duplicate and contained $0.5 \mu \mathrm{g}$ enzyme, $50 \mathrm{mM}$ HEPES $\mathrm{pH} 7,1 \mathrm{mM} \mathrm{CoSO}_{4}$ and $10 \mathrm{mM}$ of each sugar acid. Reactions were incubated for $16 \mathrm{~h}$ at $55^{\circ} \mathrm{C}$ before they were analysed using the semicarbazide assay.

\subsection{High Performance Liquid Chromatography (HPLC) Analysis}

Reactions catalysed by TaManD and standards of mannonate and KDG were analysed using an Agilent 1290 HPLC system connected to a refractive index detector (RID) G1362A (Agilent Technologies, Santa Clara, CA, USA). Samples were analysed on an organic acid column (Agilent HiPlex $\mathrm{H}^{+}$) with $10 \mathrm{mM} \mathrm{H}_{2} \mathrm{SO}_{4}$ as a mobile phase at a flow rate of $0.6 \mathrm{ml} / \mathrm{min}$. The column was heated to $80^{\circ} \mathrm{C}$ and the RID was set to $55^{\circ} \mathrm{C}$. Reactions were stopped by addition of $7 \mu \mathrm{L} 12.5 \%$ TCA to a $60 \mu \mathrm{L}$ reaction. After short centrifugation, $10 \mu \mathrm{L}$ of the supernatant was used for HPLC analysis.

\subsection{Statistical Analysis}

Statistical analysis was performed for enzyme kinetics and effect of different metals and additives on enzyme activity, by two-tailed unpaired t-tests using Prism 6.

\section{Conclusions}

In this study, we present the first purification and characterisation of a functional archaeal mannonate dehydratase. The gene encoding for the mannonate dehydratase was found adjacent to a previously described aldohexose dehydrogenase (AldT) gene in the genome of T. acidophilum [15]. 
Previously, it has been shown that AldT from T. acidophilum selectively oxidises mannose, but the physiological function behind that oxidation was not investigated. Using NMR spectroscopy, we were able to show that mannonate and mannono-1,4-lactone are produced via oxidation of D-mannose by AldT. Kinetic assays confirmed that TaManD was able to convert both the sugar acid and its lactone to the central intermediate KDG at neutral $\mathrm{pH}$, without further help of a lactonase. This resembles the second step of many oxidative pathways studied in archaea, including those for sugars like glucose, galactose, rhamnose, arabinose and xylose [39]. The amino acid sequence of TaManD and those of the putative mannonate dehydratases from $F$. acidarmanus and F. acidiphilum share high amino acid sequence identity. Although the gene annotations for those mannonate dehydratases indicate a role in the hexuronate metabolism $(u x u A)$, they are all located adjacent to (putative) aldohexose dehydrogenases. It remains to be seen whether a non-phosphorylative pathway starting from mannose, similar to the non-phosphorylative Entner-Doudoroff pathway from glucose and galactose, exists in thermophilic archaea like T. acidophilum, F. acidarmanus and F. acidiphilum.

Supplementary Materials: The following are available online at http:/ /www.mdpi.com/2073-4344/9/3/234/s1, Figure S1: Purification of the Ta0753 gene product (TaManD) after expression in E. coli, Figure S2: TaManD kinetic data Table S1: Overview of genes, potentially encoding for mannonate dehydratases located in the genomic neighbourhood of AldT (Ta0754), Table S2: Oligonucleotides used in this study.

Author Contributions: Conceptualization, D.K. and A.S.; methodology, experimental design, D.K., R.W., and A.S.; data collection, D.K.; data analysis, D.K.; writing—original draft preparation, D.K. and A.S.; writing-review and editing, D.K., R.W., and A.S.; supervision, A.S.; project administration, A.S.

Funding: D.K. is supported by an international Macquarie University Research Excellence Scholarship (iMQRES).

Acknowledgments: We thank the Australian Proteome Analysis Facility (Macquarie University, Sydney, Australia) for their support in performing LC ESI MS/MS experiments and Nicole Cordina from the Macquarie University NMR facility from the Department of Molecular Sciences for her help in performing NMR studies.

Conflicts of Interest: The authors declare no conflict of interest.

\section{References}

1. Robert-Baudouy, J.; Jimeno-Abendano, J.; Stoeber, F. D-Mannonate and D-altronate dehydratases of Escherichia coli K12. Methods Enzymol. 1982, 90, 288-294. [PubMed]

2. Shulami, S.; Gat, O.; Sonenshein, A.L.; Shoham, Y. The glucuronic acid utilization gene cluster from Bacillus stearothermophilus T-6. J. Bacteriol. 1999, 181, 3695-3704. [PubMed]

3. Mekjian, K.R.; Bryan, E.M.; Beall, B.W.; Moran, C.P. Regulation of hexuronate utilization in Bacillus subtilis. J. Bacteriol. 1999, 181, 426-433. [PubMed]

4. Hugouvieux-Cotte-Pattat, N.; Robert-Baudouy, J. Hexuronate catabolism in Erwinia Chrysanthemi. J. Bacteriol. 1987, 169, 1223-1231. [CrossRef] [PubMed]

5. Mandrand-Berthelot, M.-A.; Condemine, G.; Hugouvieux-Cotte-Pattat, N. Catabolism of hexuronides, hexuronates, aldonates, and aldarates. EcoSal Plus 2004, 1, 1-21. [CrossRef] [PubMed]

6. Reis, D.; Vian, B.; Roland, J.C. Cellulose-glucuronoxylans and plant cell wall structure. Micron 1994, 25, 171-187. [CrossRef]

7. Lawford, H.G.; Rousseau, J.D. Fermentation of biomass-derived glucuronic acid by pet expressing recombinants of E. coli B. Appl. Biochem. Biotechnol. 1997, 63-65, 221-241. [CrossRef]

8. Peekhaus, N.; Conway, T. What's for dinner?: Entner-Doudoroff metabolism in Escherichia coli. J. Bacteriol. 1998, 180, 3495-3502. [PubMed]

9. Chang, D.-E.; Smalley, D.J.; Tucker, D.L.; Leatham, M.P.; Norris, W.E.; Stevenson, S.J.; Anderson, A.B.; Grissom, J.E.; Laux, D.C.; Cohen, P.S.; et al. Carbon nutrition of Escherichia coli in the mouse intestine. Proc. Natl. Acad. Sci. USA 2004, 101, 7427-7432. [CrossRef] [PubMed]

10. Zhang, Q.; Gao, F.; Peng, H.; Cheng, H.; Liu, Y.; Tang, J.; Thompson, J.; Wei, G.; Zhang, J.; Du, Y.; et al. Crystal structures of Streptococcus suis mannonate dehydratase (ManD) and its complex with substrate: Genetic and biochemical evidence for a catalytic mechanism. J. Bacteriol. 2009, 191, 5832-5837. [CrossRef] [PubMed] 
11. Qiu, X.; Tao, Y.; Zhu, Y.; Yuan, Y.; Zhang, Y.; Liu, H.; Gao, Y.; Teng, M.; Niu, L. Structural insights into decreased enzymatic activity induced by an insert sequence in mannonate dehydratase from Gram negative bacterium. J. Struct. Biol. 2012, 180, 327-334. [CrossRef] [PubMed]

12. Wichelecki, D.J.; Balthazor, B.M.; Chau, A.C.; Vetting, M.W.; Fedorov, A.A.; Fedorov, E.V.; Lukk, T.; Patskovsky, Y.V.; Stead, M.B.; Hillerich, B.S.; et al. Discovery of function in the enolase superfamily: D-mannonate and D-gluconate dehydratases in the D-mannonate dehydratase subgroup. Biochemistry 2014, 53, 2722-2731. [CrossRef] [PubMed]

13. Wichelecki, D.J.; Alyxa, J.; Vendiola, F.; Jones, A.M.; Al-obaidi, N.; Almo, S.C.; Gerlt, J.A. Investigating the physiological roles of low-efficiency D-mannonate and D-gluconate dehydratases in the enolase superfamily: pathways for the catabolism of L-gulonate and L-idonate. Biochemistry 2014, 53, 5692-5699. [CrossRef] [PubMed]

14. Rakus, J.F.; Fedorov, A.A.; Fedorov, E.V.; Glasner, M.E.; Vick, J.E.; Babbitt, P.C.; Almo, S.C.; Gerlt, J.A. Evolution of enzymatic activities in the enolase superfamily: D-mannonate dehydratase from Novosphingobium aromaticivorans. Biochemistry 2007, 46, 12896-12908. [CrossRef] [PubMed]

15. Nishiya, Y.; Tamura, N.; Tamura, T. Analysis of bacterial glucose dehydrogenase homologs from thermoacidophilic archaeon Thermoplasma acidophilum: finding and characterization of aldohexose dehydrogenase. Biosci. Biotechnol. Biochem. 2014, 68, 2451-2456. [CrossRef] [PubMed]

16. Yasutake, Y.; Nishiya, Y.; Tamura, N.; Tamura, T. Structural Insights into unique substrate selectivity of Thermoplasma acidophilum D-aldohexose dehydrogenase. J. Mol. Biol. 2007, 367, 1034-1046. [CrossRef] [PubMed]

17. Kim, S.; Lee, S.B. Catalytic promiscuity in dihydroxy-acid dehydratase from the thermoacidophilic archaeon Sulfolobus solfataricus. J. Biochem. 2006, 139, 591-596. [CrossRef] [PubMed]

18. Ashwell, G. [21] Enzymes of glucuronic and galacturonic acid metabolism in bacteria. In Methods in enzymology; Academic Press: Cambridge, MA, USA, 1962; Volume 5, pp. 190-208, ISBN 0076-6879.

19. Portalier, R.; Robert-Baudouy, J.; Stoeber, F. Regulation of Escherichia coli K-12 hexuronate system genes: exu regulon. J. Bacteriol. 1980, 143, 1095-1107. [PubMed]

20. Palleroni, N.J.; Duodoroff, M. Metabolism of Carbohydrate by Pseudomonas Saccharophila III. Oxidation of Arabinose. J. Bacteriol. 1957, 74, 180-185. [PubMed]

21. Watanabe, S.; Saimura, M.; Makino, K. Eukaryotic and bacterial gene clusters related to an alternative pathway of nonphosphorylated L-rhamnose metabolism. J. Biol. Chem. 2008, 283, 20372-20382. [CrossRef] [PubMed]

22. Stephens, C.; Christen, B.; Fuchs, T.; Sundaram, V.; Watanabe, K.; Jenal, U. Genetic analysis of a novel pathway for D-xylose metabolism in Caulobacter crescentus. J. Bacteriol. 2007, 189, 2181-2185. [CrossRef] [PubMed]

23. Wałaszek, Z.; Horton, D. Conformational studies on aldonolactones by NMR spectroscopy. Conformations of d-glucono-, D-mannono, D-gulono-, D-galactono-1,4-lactone in solution. Carbohydr. Res. 1982, 105, $131-143$. [CrossRef]

24. Dreyer, J. The role of iron in the activation of mannonic and altronic acid hydratases, two Fe-requiring hydro-lyases. Eur. J. Biochem 1987, 166, 623-630. [CrossRef] [PubMed]

25. Robert-Baudouy, J.M.; Jimeno-Abendano, J.; Stoeber, F.R. Individualité des hydrolyases mannonique et altronique chez E. coli K-12. Biochimie 1975, 57, 1-8. [CrossRef]

26. Robert-Baudouy, J.M.; Stoeber, F.R. Purification et propriétés de la D-mannonate hydrolyase d'Escherichia coli. Biochim. Biophys. Acta-Enzymology 1973, 309, 473-485. [CrossRef]

27. Darland, G.; Brock, T.D.; Samsonoff, W.; Conti, S.F. A thermophilic, acidophilic mycoplasma isolated from a coal refuse pile. Science 1970, 170, 1416-1418. [CrossRef] [PubMed]

28. Jung, J.H.; Lee, S.B. Identification and characterization of Thermoplasma acidophilum 2-keto-3-deoxy-D-gluconate kinase: A new class of sugar kinases. Biotechnol. Bioprocess Eng. 2005, 10, 535-539. [CrossRef]

29. Kim, S.M.; Paek, K.H.; Lee, S.B. Characterization of NADP ${ }^{+}$-specific L-rhamnose dehydrogenase from the thermoacidophilic Archaeon Thermoplasma acidophilum. Extremophiles 2012, 16, 447-454. [CrossRef] [PubMed] 
30. Reher, M.; Schönheit, P. Glyceraldehyde dehydrogenases from the thermoacidophilic euryarchaeota Picrophilus torridus and Thermoplasma acidophilum, key enzymes of the non-phosphorylative Entner-Doudoroff pathway, constitute a novel enzyme family within the aldehyde dehydrogenase superfamily. FEBS Lett. 2006, 580, 1198-1204. [PubMed]

31. Yew, W.S.; Fedorov, A.A.; Fedorov, E.V.; Rakus, J.F.; Pierce, R.W.; Almo, S.C.; Gerlt, J.A. Evolution of enzymatic activities in the enolase superfamily: L-fuconate dehydratase from Xanthomonas campestris. Biochemistry 2006, 45, 14582-14597. [CrossRef] [PubMed]

32. Carsten, J.M.; Schmidt, A.; Sieber, V. Characterization of recombinantly expressed dihydroxy-acid dehydratase from Sulfobus solfataricus-A key enzyme for the conversion of carbohydrates into chemicals. J. Biotechnol. 2015, 211, 31-41. [CrossRef] [PubMed]

33. Sambrook, J.; Russell, D.W.; Russell, D.W. Molecular Cloning: A Laboratory Manual; Cold Spring Harbor Laboratory Press: New York, NY, USA, 2001; Volume 49, ISBN 978-1-936113-42-2.

34. Atack, J.M.; Srikhanta, Y.N.; Fox, K.L.; Jurcisek, J.A.; Brockman, K.L.; Clark, T.A.; Boitano, M.; Power, P.M.; Jen, F.E.C.; McEwan, A.G.; et al. A biphasic epigenetic switch controls immunoevasion, virulence and niche adaptation in non-typeable Haemophilus influenzae. Nat. Commun. 2015, 6, 1-12. [CrossRef] [PubMed]

35. Lamble, H.J.; Milburn, C.C.; Taylor, G.L.; Hough, D.W.; Danson, M.J. Gluconate dehydratase from the promiscuous Entner-Doudoroff pathway in Sulfolobus solfataricus. FEBS Lett. 2004, 576, 133-136. [CrossRef] [PubMed]

36. Buchanan, C.L.; Connaris, H.; Danson, M.J.; Reeve, C.D.; Hough, D.W. An extremely thermostable aldolase from Sulfolobus solfataricus with specificity for non-phosphorylated substrates. Biochem. J. 1999, 343, 563-570. [CrossRef] [PubMed]

37. Skoza, L.; Mohos, S. Stable thiobarbituric acid chromophore with dimethyl sulphoxide. Application to sialic acid assay in analytical de-O-acetylation. Biochem. J. 1976, 159, 457-462. [CrossRef] [PubMed]

38. Britton, H.T.S.; Robinson, R.A. CXCVIII.-Universal buffer solutions and the dissociation constant of veronal. J. Chem. Soc. 1931, 1456-1462. [CrossRef]

39. Bräsen, C.; Esser, D.; Rauch, B.; Siebers, B. Carbohydrate metabolism in archaea: current insights into unusual enzymes and pathways and their regulation. Microbiol. Mol. Biol. Rev. 2014, 78, 89-175. [CrossRef] [PubMed]

(C) 2019 by the authors. Licensee MDPI, Basel, Switzerland. This article is an open access article distributed under the terms and conditions of the Creative Commons Attribution (CC BY) license (http:/ / creativecommons.org/licenses/by/4.0/). 